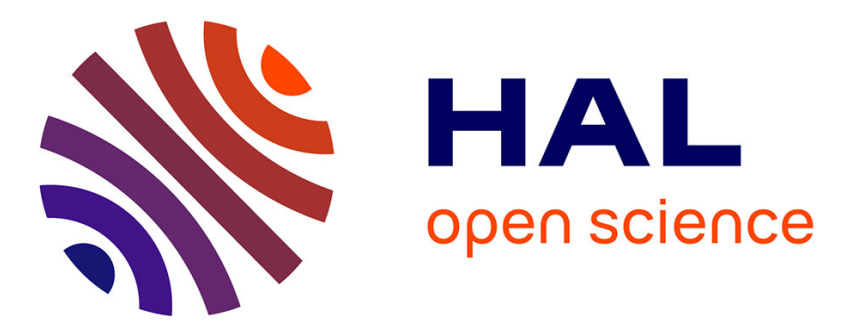

\title{
Addition de lipides protégés (encapsulés ou savons de calcium) à la ration de vaches laitières. Effets sur les performances et la composition du lait
}

\author{
Y. Chilliard, M. Doreau, G. Gagliostro, Y. Elmeddah
}

\section{- To cite this version:}

Y. Chilliard, M. Doreau, G. Gagliostro, Y. Elmeddah. Addition de lipides protégés (encapsulés ou savons de calcium) à la ration de vaches laitières. Effets sur les performances et la composition du lait. Productions Animales, 1993, 6 (2), pp.139-150. hal-00896050

\section{HAL Id: hal-00896050 \\ https://hal.science/hal-00896050}

Submitted on 1 Jan 1993

HAL is a multi-disciplinary open access archive for the deposit and dissemination of scientific research documents, whether they are published or not. The documents may come from teaching and research institutions in France or abroad, or from public or private research centers.
L'archive ouverte pluridisciplinaire HAL, est destinée au dépôt et à la diffusion de documents scientifiques de niveau recherche, publiés ou non, émanant des établissements d'enseignement et de recherche français ou étrangers, des laboratoires publics ou privés. 
INRA Prod. Anim., 1993, 6 (2), 139 - 150
Y. CHILLIARD, M. DOREAU, G. GAGLIOSTRO*, Y. ELMEDDAH**

INRA Laboratoire Sous-Nutrition des Ruminants,

Theix, 63122 Saint-Genès-Champanelle

* Instituto Nacional de Technologia Agropecuaria, CC 276, 7620 Balcarce, Argentine

**INES Agronomie, Route de Hasnaoua, 15000 Tizi-Ouzou, Algérie

\section{Addition de lipides protégés (encapsulés ou savons de calcium) à la ration de vaches laitières.} Effets sur les performances
et la composition du lait.

L'intérêt de l'addition de matières grasses dans les rations pour vaches laitières reste controversé. Cet article fait le point sur les effets de lipides "protégés" sur la production et la composition du lait.

L'incorporation de suppléments lipidiques dans la ration des ruminants, particulièrement des vaches laitières, se développe depuis plusieurs années. La haute valeur énergétique des lipides, associée à un coût raisonnable, leur permet d'entrer dans la composition d'aliments concentrés proposés dans les gammes des principaux fabricants. On en attend des effets bénéfiques sur la production laitière, lorsqu'ils permettent un accroissement de la consommation d'énergie, ou sur la

\section{Résumé}

L'une des limites à l'utilisation des matières grasses dans l'alimentation des ruminants tient aux perturbations qu'elles engendrent dans la digestion des glucides dans le rumen. Pour éviter cet inconvénient, diverses formes de protection des lipides sont apparues. Cet article récapitule les effets de l'addition des graisses animales (en moyenne $941 \mathrm{~g} / \mathrm{j}$ ) et d'huiles végétales $(693 \mathrm{~g} / \mathrm{j}$ ) encapsulées, et de savons de calcium $(593 \mathrm{~g} / \mathrm{j})$, dans la ration des vaches laitières sur les quantités ingérées, la production et la composition du lait.

L'addition de matières grasses protégées entraîne une diminution des quantités ingérées plus faible pour les savons de calcium $(0,55 \mathrm{~kg} \mathrm{MS} / \mathrm{jour})$ que pour les graisses ou les huiles encapsulées $(1,1$ à $1,3 \mathrm{~kg} \mathrm{MS} / \mathrm{jour})$. Ces diminutions sont comparables à celles observées avec des matières grasses non protégées.

L'incorporation de graisses encapsulées ou de savons de calcium accroît la production laitière d'environ $1 \mathrm{~kg} /$ jour, alors que celle d'huiles encapsulées ne la modifie pas. L'addition de graisses encapsulées ou de savons de calcium réduit le taux protéique de 1,8 et $1,2 \mathrm{~g} / \mathrm{kg}$, respectivement, alors que les huiles encapsulées ne le modifient pas. Cette différence est une conséquence des variations de production laitière, la quantité de protéines sécrétée n'étant modifiée par aucun des trois suppléments. L'encapsulation des lipides entraîne un accroissement important $d u$ taux butyreux avec les graisses $(4,0 \mathrm{~g} / \mathrm{kg})$ et les huiles $(6,4 \mathrm{~g} / \mathrm{kg})$. L'augmentation de sécrétion d'acides gras longs est en effet supérieure à la réduction de la synthèse de novo d'acides gras courts et moyens. L'accroissement variable de la sécrétion d'acides gras polyinsaturés reflète l'efficacité de la protection contre l'hydrogénation ruminale. L'addition de savons de calcium n'accroît pas le taux butyreux ; selon les essais, l'inhibition de la synthèse de novo est compensée par une sécrétion accrue soit d'acide palmitique, soit d'acide oléique. mobilisation des réserves (Chilliard 1993) et peut-être sur la reproduction. En revanche, on redoute leurs effets globalement négatifs sur le taux protéique, bien que la production de protéines ne varie que faiblement (Doreau et Chilliard 1992), et sur la digestion dans le rumen, souvent perturbée par l'addition aux rations de matières grasses n'ayant pas subi de traitements technologiques. La digestibilité des parois végétales, en particulier, est réduite, et le profil des acides gras volatils est orienté en faveur de l'acide propionique (Palmquist et Jenkins 1980, Tamminga et Doreau 1991). Cette dernière conséquence entraîne des modifications de l'utilisation métabolique des glucides, et donc entre autres de la teneur et de la composition des matières grasses du lait (Chilliard et al 1986). La diminution de la digestibilité des parois, pour sa part, a pour effet de diminuer la valeur énergétique de la fraction non lipidique des rations, et par là même contribue à réduire l'intérêt d'un apport supplémentaire de lipides.

Cette action négative des matières grasses sur la dégradation des glucides n'est pas systématique (Tamminga et Doreau 1991). Elle est modérée lorsque les acides gras apportés sont saturés ou monoinsaturés, lorsque le régime est bien pourvu en calcium soluble, lorsque la ration est riche en foin. Mais à l'heure actuelle il n'est pas encore possible de maîtriser sans risque d'échec l'ampleur des perturbations digestives. Aussi diverses techniques de protection des lipides dans le rumen (voir encadré) ont-elles été expérimentées depuis les années 70 : l'encapsulation de matières grasses dans une coque de protéines tannées au formaldéhyde, la saponification, et la cristallisation de triglycérides d'origine animale ou d'acides gras saturés (parmi lesquels les "fat prills"). Cette dernière technique ne 


\section{Les techniques de protection des lipides}

La protection des lipides par encapsulation est la technique la plus ancienne. Décrite par Scott et al (1971), elle se caractérise par une protection seulement partielle des matières grasses contre l'hydrogénation (Ashes et al 1979). Par rapport aux premiers essais in vitro qui montraient une excellente efficacité du produit, l'utilisation à grande échelle chez l'animal s'est révélée plus délicate (Doreau et al 1991). La mastication du produit entraîne une rupture de la structure de l'aliment, et donc une libération plus facile des lipides dans le rumen, ce qui réduirait de 15 à 25 points le coefficient de protection in vivo par rapport à celui qui est déterminé in vitro (Ashes et al 1979). De plus, la maîtrise de la technique de protection peut être variable selon la fabrication. Toutefois, cette technique est la seule jusqu'à présent à s'être traduite par l'absorption digestive de quantités élevées d'acides gras polyinsaturés, ayant échappé à l'hydrogénation dans le rumen.

L'utilisation des savons de calcium est plus récente (Palmquist el Jenkins 1982). Elle s'est fondée sur l'observation de l'effet bénéfique du calcium pour éviter les perturbations de la digestion dans le rumen (Devendra et Lewis 1974), attribué à la formation de savons insolubles d'acides gras et de calcium. On sait maintenant que les mécanismes d'action du calcium sont plus complexes, mais il a été montré que les savons de calcium ne perturbalent pas la digestion dans le rumen, quel que soit le type de ration (Elmeddah et a 1991). Toutefois, ils n'échappent qu'en partie à l'hydrogénation (Ferlay et al 1992), preuve de leur dissociation au moins partielle dans le rumen.

sera pas étudiée ici, car les mécanismes de protection dans le rumen ne sont pas encore établis, et les essais d'alimentation sont en nombre restreint.

Les matières grasses encapsulées et les savons de calcium ont fait l'objet d'une analyse des données bibliographiques afin de préciser les effets de leur incorporation sur les performances laitières, en dégageant un effet moyen, et éventuellement des facteurs de variation.

Les matières grasses encapsulées peuvent être réparties en deux sous-groupes de nature différente. D'une part les graisses animales encapsulées (GAE), presque exclusivement du suif, sont riches en acides gras saturés et monoinsaturés à 16 et 18 atomes de carbone : palmitique, stéarique et oléique (26 comparaisons entre lots supplémentés et lots témoins). D'autre part, les graines ou huiles végétales encapsulées (HVE) contiennent des proportions élevées d'acides gras polyinsaturés ( 26 comparaisons, dont 3 où l'huile a été directement infusée dans la caillette ou le duodénum). Les matières grasses utilisées proviennent principalement $d u$ carthame et du soja, mais aussi du tournesol et du colza. Leur composition en acides gras est précisée dans le tableau 1.

Les savons de calcium (SC) actuellement commercialisés sont à base d'huile de palme, riche en acide palmitique et en acide oléique (tableau 1). Dans la présente analyse, $29 \mathrm{com}$ paraisons ont été prises en compte.

On remarquera que la quantité d'acides gras incorporée a été en moyenne plus élevée pour les graisses animales encapsulées $(941 \mathrm{~g} / \mathrm{j})$ que pour les huiles végétales encapsulées ou les savons de calcium (respectivement 693 et $593 \mathrm{~g} / \mathrm{j}$ ).

\section{1 / Ingestion de matière sèche et d'énergie}

Lorsque la ration est supplémentée en lipides, une réduction du niveau d'ingestion est observée avec les trois sources de matières grasses, mais est plus sensible pour les lipides encapsulés (figure 1). La quantité de matière sèche ingérée par jour diminue en moyenne de 2,6 et $1,8 \mathrm{~kg}$ pour les HVE $(\mathrm{r}=-0,82 ; \mathrm{n}=12)$ et les GAE ( $r=-0,68 ; n=21)$ pour une addi-

Tableau 1. Composition (\% pondéral) en acides gras de différentes sources lipidiques (d'après Doreau et al 1987, Karleskind 1992 et documents Volac Ltd).

\begin{tabular}{|l|c|c|c|c|c|}
\hline & $\begin{array}{c}\text { C16:0 } \\
\text { (palmitique) }\end{array}$ & $\begin{array}{c}\text { C18:0 } \\
\text { (stéarique) }\end{array}$ & $\begin{array}{c}\text { C18:1 } \\
\text { (oléique) }\end{array}$ & $\begin{array}{c}\text { C18:2 } \\
\text { (linoléique) }\end{array}$ & $\begin{array}{c}\text { C18:3 } \\
\text { (linolénique) }\end{array}$ \\
\hline Suif & $24-28$ & $15-29$ & $31-42$ & $1-4$ & $0-2$ \\
Huile de soja & $10-13$ & $1-5$ & $22-31$ & $48-55$ & $5-9$ \\
Huile de carthame & $6-7$ & $2-3$ & $10-20$ & $68-83$ & $0-1$ \\
variétés "linoléiques" & $2-6$ & $1-2$ & $50-66$ & $18-30$ & $6-14$ \\
Huile de colza & 46 & 4 & 43 & 8 & 0 \\
Huile de palme incorporée & & & & & \\
dans les savons & & & & & \\
\hline
\end{tabular}

${ }^{1}$ L'huile de carthame provient d'une graine oléagineuse cultivée essentiellement aux USA, mais aussi en Europe du Sud. Il existe des variétés oléiques et linoléiques.

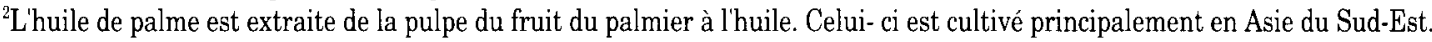


Figure 1. Variations des quantités ingérées de matière sèche ( $\triangle M S I$, en $\mathrm{kg} M S$ ) par rapport à un régime témoin, en fonction de la nature et de la quantité de matières grasses ou de savons ajoutés à la ration.
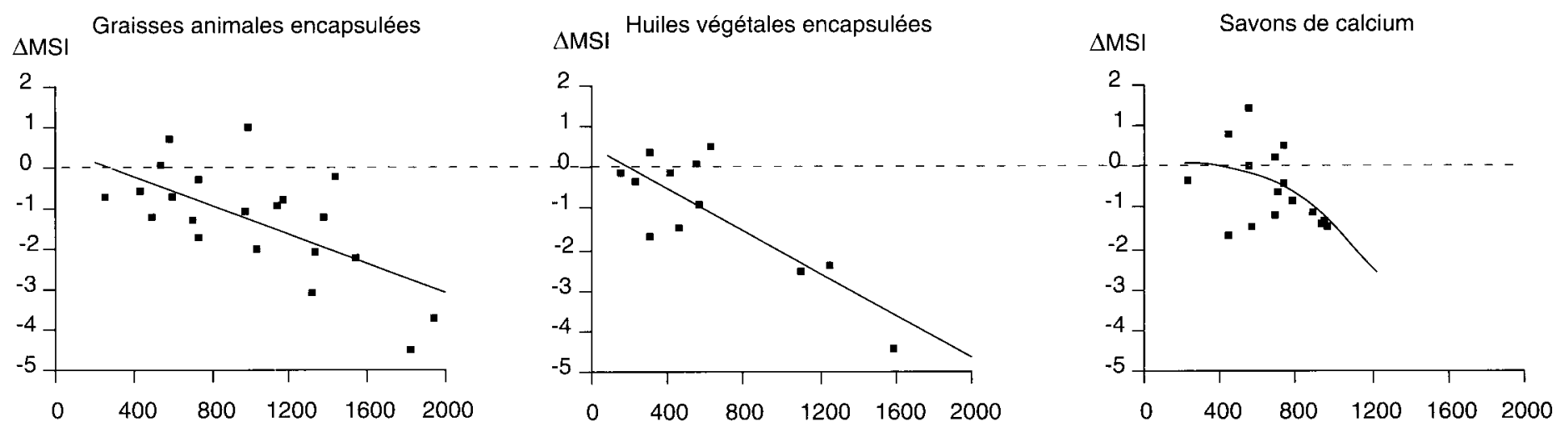

Quantité de matières grasses ou de savons $(\mathrm{g} / \mathrm{j})$

Ces résultats, ainsi que ceux des figures 2 et 3 , sont issus des publications suivantes

- graisses animales encapsulées:

Banks et al 1984, Bines et al 1978, Kronfeld et al 1980, Macleod et al 1977, Murphy et Morgan 1983, Sharma et al 1978, Smith et al 1978, Vicente et al 1984, Wilson et Brookes 1975, Wrenn et al 1978. - huiles végétales encapsulées:

Barbano et Sherbon 1980, Bitman et al 1973, Gagliostro et Chilliard 1991, Goering et al 1976, 1977, Gooden et Lascelles 1973, Grummer et al 1987, Mattos et Palmquist 1974, Palmquist et Moser 1981, Pan et al 1972, Plowman et al 1972, Radcliffe et Bartsch 1975, Rindsig et Schultz 1974, Storry et al 1974, Wrenn et al 1976.

- savons de calcium:

Baker et al 1989, Burgess et al 1987, Chilliard et al non publié, Crovetto et al 1989, Doreau et al 1991, Downer et al 1987, Eastridge et Palmquist 1988, Erickson et al 1992, Ferguson et al 1988, 1989 Grummer 1988, Harris et Webb 1988, Kent et Arambel 1988, Klusmeyer et al 1989, Klusmeyer et Clark 1991, Palmquist 1984a, Palmquist 1988, Robb et Chalupa 1987, Schauff et Clark 1989, Schneider et al 1988, Umphrey et al 1989.

tion de $1 \mathrm{~kg}$ de lipides. Cette diminution, du même ordre de grandeur ou supérieure à celle qui est observée avec des lipides non protégés, peut être attribuée à deux facteurs. D'une part, lorsque les matières grasses encapsulées sont incomplètement protégées de la dégradation ruminale, la vitesse de digestion des glucides est certainement ralentie, en particulier avec les HVE plus riches en acides gras polyinsaturés. Une des conséquences en est l'accroissement de l'encombrement du rumen, qui peut contribuer à diminuer les quantités ingérées. D'autre part, les lipides ont une action métabolique négative sur les quantités ingérées, comme l'ont montré entre autres deux essais de Gagliostro et Chilliard (1991) et Chilliard et Doreau (1991) avec des infusions d'huile de colza dans le duodénum.

Dans le cas des $\mathrm{SC}$, la réponse n'est pas linéaire. Les quantités ingérées ne sont réduites qu'au-delà d'un apport journalier de $700 \mathrm{~g}$ environ. Ce moindre effet négatif des SC pourrait être dû à l'absence de réduction de la digestion dans le rumen. L'effet métabolique des lipides sur l'ingestion ne serait sensible qu'à partir d'un niveau seuil d'apport, d'environ 600 à $800 \mathrm{~g} / \mathrm{j}$ (figure 1 ).

L'un des buts de l'incorporation de matières grasses dans la ration des vaches laitières est d'augmenter la quantité d'énergie ingérée. Les informations disponibles dans les publications analysées n'ont pas toujours permis de calculer l'énergie ingérée par les animaux avec une précision suffisante. Par ailleurs, la valeur énergétique nette des suppléments lipidiques varie très fortement d'un système énergétique à l'autre (Vermorel et al 1986) et selon les suppléments lipidiques ou les conditions expérimentales (Chilliard 1993). Il semble toutefois qu'avec des lipides encapsulés l'ingestion d'énergie ne soit que faiblement améliorée, du fait de la réduction de la matière sèche ingérée : de 6 à $7 \%$ avec les HVE (Goering et al 1977, Astrup et al 1979, Storry et al 1980b) ; de 5 à $6 \%$ avec les GAE (Murphy et Morgan 1983, Vicente et al 1984). Avec ces dernières, l'ingestion d'énergie peut parfois être réduite de 2 à $5 \%$ (McLeod et al 1977, Bines et al 1978, Smith et al 1978). Dans le cas des SC, l'énergie ingérée est légèrement augmentée (+1,1 Mcal d'énergie nette/j dans 29 lots de vaches supplémentées ; Chilliard 1993). Toutefois, aussi bien avec les GAE qu'avec les $\mathrm{SC}$ on observe que le bilan énergétique n'est pas accru, et même baisse parfois, en raison de l'accroissement de l'énergie sécrétée dans le lait (Chilliard 1993).

\section{2 / Production laitière}

\section{1 / Graisses animales encapsulées}

L'incorporation de GAE entraîne un accroissement significatif $(\mathrm{P}<0,01)$ de la production de lait brut d'environ $1 \mathrm{~kg} / \mathrm{j}$ (tableau 2). On peut toutefois remarquer que des effets positifs significatifs ne sont enregistrés que dans $35 \%$ des essais. Cette variabilité importante des résultats s'explique par la diversité des protocoles expérimentaux : ainsi le taux d'incorporation de GAE est très variable d'un essai à l'autre ; le fait que les lipides aient été apportés en addition ou en substitution à d'autres sources énergétiques glucidiques; le bilan énergétique, positif ou négatif, peuvent être autant de facteurs contribuant à cette variabilité. Malgré une grande hétérogénéité de résultats, on note une influence du niveau d'apport de GAE. La réponse tend à être curvilinéaire $(r=0,58, P<0,01)$ et montre un maximum de réponses positives entre 500 et $1500 \mathrm{~g} / \mathrm{j}$ de
L'addition de lipides protégés entraîne une diminution des quantités consommées et l'énergie totale ingérée n'est que légèrement augmentée. 
Tableau 2. Effets d'un apport de matières grasses encapsulées ou de savons de calcium sur lingestion et les performances laitières des vaches.

\begin{tabular}{|c|c|c|c|c|c|c|}
\hline \multirow{2}{*}{$\begin{array}{l}\text { Type de matières } \\
\text { grasses et niveau } \\
\text { d'apport } \\
\text { (1) }\end{array}$} & \multirow{2}{*}{$\begin{array}{c}\text { Nombre } \\
\text { d'observations } \\
\text { (2) }\end{array}$} & \multirow[t]{2}{*}{ Paramètres } & \multirow[b]{2}{*}{$\begin{array}{l}\text { Effet } \\
\text { moyen } \\
(3)\end{array}$} & \multicolumn{3}{|c|}{ Fréquence des effets (\%) } \\
\hline & & & & $\begin{array}{c}\text { Positifs } \\
\text { (4) }\end{array}$ & Nuls & $\begin{array}{c}\text { Négatifs } \\
\text { (4) }\end{array}$ \\
\hline & 12 & Quantités ingérées (kg MS/j) & $-1,08^{*}$ & 0 & 58 & 42 \\
\hline Huiles végétales & 20 & Lait $(\mathrm{kg} / \mathrm{j})$ & $-0,04$ & 15 & 80 & 5 \\
\hline encapsulées & 26 & Taux butyreux (g/kg) & $+6,4^{* *}$ & 77 & 23 & 0 \\
\hline$(693 \pm 410 \mathrm{~g} / \mathrm{j})$ & 16 & Taux protéique (g/kg) & $-0,8$ & 6 & 50 & 44 \\
\hline & 21 & Quantités ingérées (kg MS/j) & $-1,26^{* *}$ & 0 & 43 & 57 \\
\hline Graisses animales & 26 & Lait $(\mathrm{kg} / \mathrm{j})$ & $+0,97^{*}$ & 35 & 65 & 0 \\
\hline encapsulées & 26 & Taux butyreux (g/kg) & $+4,0^{* * *}$ & 73 & 27 & 0 \\
\hline$(941 \pm 440 \mathrm{~g} / \mathrm{j})$ & 24 & Taux protéique (g/kg) & $-1,8^{* *}$ & 0 & 37 & 63 \\
\hline & 16 & Quantités ingérées (kg MS/j) & $-0,55^{* *}$ & 0 & 75 & 25 \\
\hline Savons de calcium & 29 & Lait $(\mathrm{kg} / \mathrm{j})$ & $+0,94^{* * *}$ & 34 & 59 & 7 \\
\hline d'huile de palme & 29 & Taux butyreux (g/kg) & $+0,4$ & 28 & 72 & 0 \\
\hline$(593 \pm 183 \mathrm{~g} / \mathrm{j})$ & 25 & Taux protéique (g/kg) & $-1,2^{* *}$ & 0 & 72 & 28 \\
\hline
\end{tabular}

(1) Quantité de matières grasses (huiles et graisses) ou de savons (contenant environ $85 \%$ d'acides gras).

(2) Nombre de différences entre lots lipides et lots témoins.

(3) Moyenne inter-essais des différences entre les groupes supplémentés en lipides et les groupes témoins (test t de Student pour des données appariées, ${ }^{*}{ }^{* *}: \mathrm{P}<0,05$ et $\mathrm{P}<0,01$ ).

(4) Fréquence des effets significatifs (intra-essai) par rapport au lot témoin.

GAE (figure 2). Les réponses les plus négatives sont observées au-delà de $1600 \mathrm{~g} / \mathrm{j}$. Ce résultat est très voisin de celui obtenu par Storry et al (1980a) sur une partie des données analysées dans le présent article. Il ne semble pas que la réponse à la distribution de GAE dépende du niveau de production des vaches, pour des niveaux moyens variant entre 9 et $32 \mathrm{~kg} / \mathrm{j}$ selon les essais.

\section{2 / Huiles végétales encapsulées}

Avec les HVE, la fréquence d'effets favorables est réduite $(15 \%)$ et celle des effets nuls augmente $(80 \%)$ d'où un effet moyen voisin de zéro $(-0,04 \mathrm{~kg} / \mathrm{j}$; tableau 2$)$. La réponse au taux d'incorporation des HVE est similaire à celle obtenue avec les GAE (curvilinéaire, $r=0,66$, $\mathrm{P}<0,01$ ), mais des effets négatifs, de l'ordre de
$2 \mathrm{~kg} / \mathrm{j}$ de lait, sont obtenus à partir d'une ingestion d'HVE de $1200 \mathrm{~g} / \mathrm{j}$ (figure 2). Le niveau de production (entre 15 et $35 \mathrm{~kg} / \mathrm{j}$ selon les essais) n'est pas un facteur déterminant de la réponse de la production laitière à l'ingestion d'HVE. Il est difficile d'expliquer le faible effet des HVE sur la production laitière. Il est possible qu'étant donné la relative ancienneté des travaux menés avec cette source de matières grasses, les conditions permettant d'optimiser la production de lait, en particulier une nutrition protéique adéquate, n'aient pas été réunies.

\section{3 / Savons de calcium}

Les études menées avec des SC ont concerné des vaches produisant en moyenne de 20 à $45 \mathrm{~kg} / \mathrm{j}$ de lait selon les essais. Cette différence

Figure 2. Variations de la production laitière $(\triangle P L$, en $\mathrm{kg})$ par rapport à un régime témoin, en fonction de la nature et de la quantité de matières grasses ou de savons ajoutés à la ration.
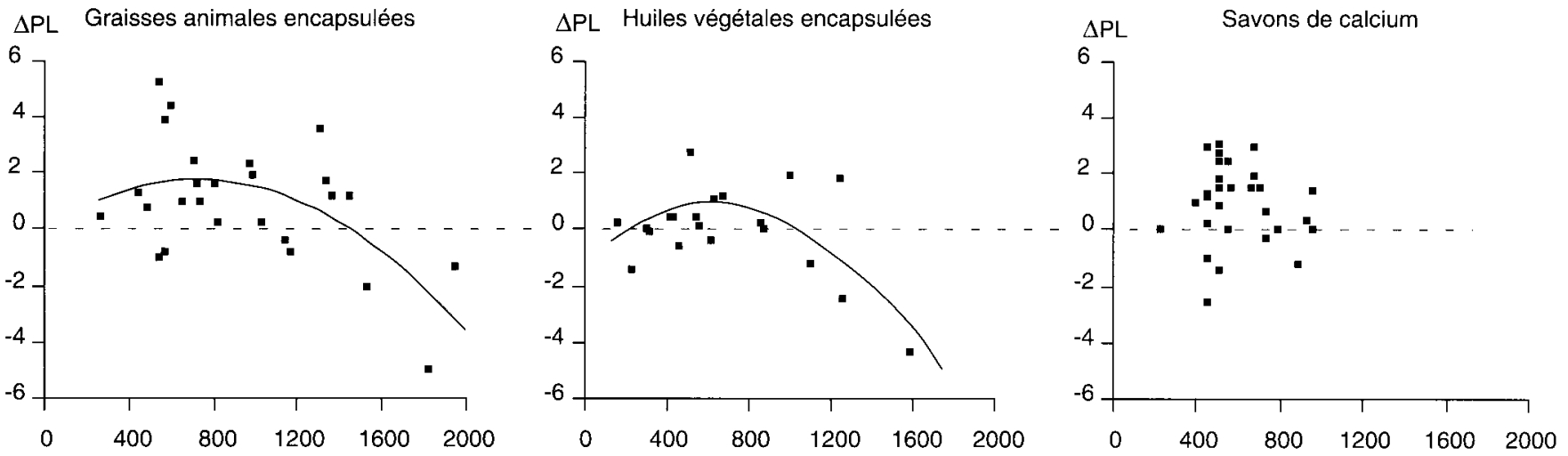

Quantité de matières grasses ou de savons $(\mathrm{g} / \mathrm{j})$ 
de potentiel laitier avec les essais sur lipides encapsulés est due au fait que les expérimentations sur SC sont plus récentes, en majorité postérieures à 1987. Toutefois, comme l'effet de l'addition de $\mathrm{SC}$ a été, comme pour les GAE et les HVE, indépendant du niveau de production, on peut considérer que les comparaisons entre les trois formes de lipides protégés ne sont pas biaisées. La production laitière s'est accrue de près de $1 \mathrm{~kg} / \mathrm{j}$ en moyenne, sans qu'il soit possible de relier la réponse à la quantité de SC ajoutée (figure 2). Ceci pourrait être dû à la plage de supplémentation relativement faible utilisée dans les expérimentations (de 400 à $700 \mathrm{~g} / \mathrm{j}$ dans $72 \%$ des cas). De plus, la quasi absence d'études d'un "effet dose" permet difficilement de mettre en évidence un seuil de réponse.

\section{3 / Taux protéique}

L'effet de l'addition de lipides protégés sur le taux protéique est généralement négatif. Ceci semble être plus net dans le cas des GAE et des SC que des HVE (tableau 2). Les GAE conduisent à des diminutions de taux protéique dans $63 \%$ des essais $(-1,8 \mathrm{~g} / \mathrm{kg}$ en moyenne, $\mathrm{P}<0,01$ ) alors que les HVE n'y conduisent que dans $44 \%$ des essais avec un effet global non significatif. L'addition de SC n'entraîne une diminution significative du taux protéique que dans $28 \%$ des cas, mais l'effet moyen est négatif $(-1,2 \mathrm{~g} / \mathrm{kg}, \mathrm{P}<0,01)$. Les effets dits nuls correspondent le plus souvent à des tendances négatives, bien que non significatives.

Aucune relation linéaire $(\mathrm{P}>0,10)$ ou curvilinéaire n'a pu être mise en évidence entre la variation de taux protéique et le niveau d'apport de lipides (figure 3 ) : pour chaque classe de matières grasses il existe une très grande variabilité. Dans certains essais comme celui de Wrenn et al (1976), le taux protéique tend à remonter pour un apport très élevé de lipides, mais ce n'est certainement qu'une conséquence passive d'une chute importante de production laitière.

La protection des lipides n'entraîne donc pas d'effet spécifique sur le taux protéique. Les principales conclusions établies dans le cas général de la supplémentation lipidique (Doreau et Chilliard 1992) se vérifient. Par exemple, la chute de taux protéique lors d'un apport de matières grasses est indépendante
L'apport de graisses encapsulées ou de savons fait diminuer le TP, essentiellement par effet de dilution, les quantités de protéines sécrétées variant peu.

Figure 3. Variations du taux butyreux $(\triangle T B$, en $\mathrm{g} / \mathrm{kg}$ ) et du taux protéique $(\Delta T P$, en $\mathrm{g} / \mathrm{kg}$ ) par rapport à un régime témoin, en fonction de la nature et de la quantité de matières grasses ou de savons ajoutés à la ration.

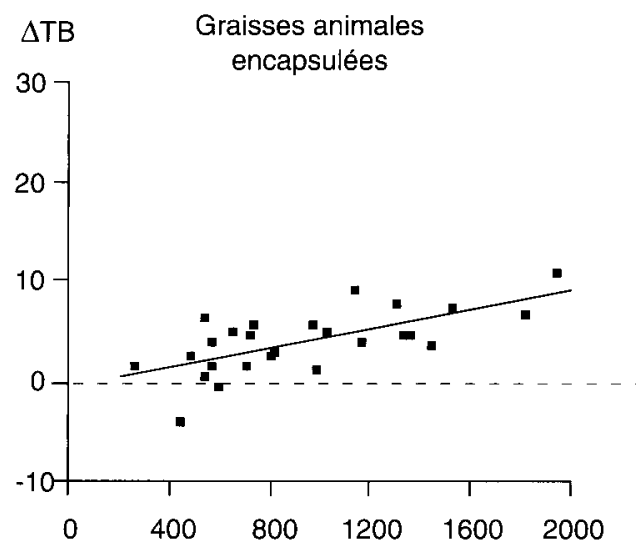

$\Delta$ TB Huiles végétales encapsulées

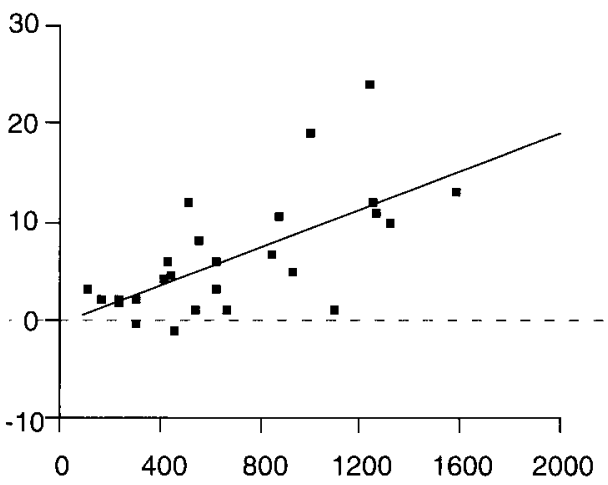

Quantité de matières grasses ou de savons $(\mathrm{g} / \mathrm{j})$
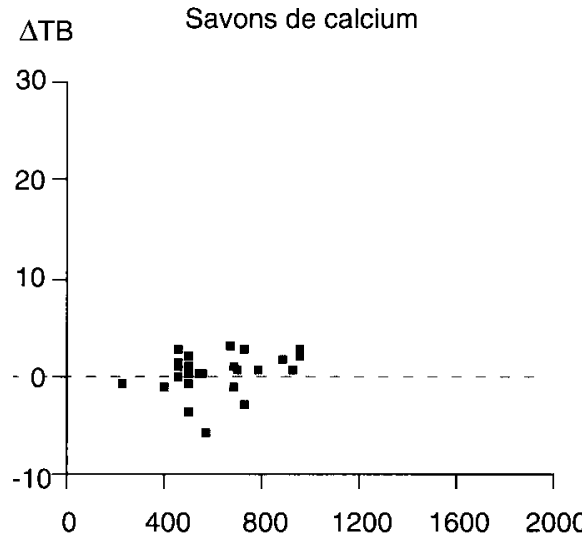
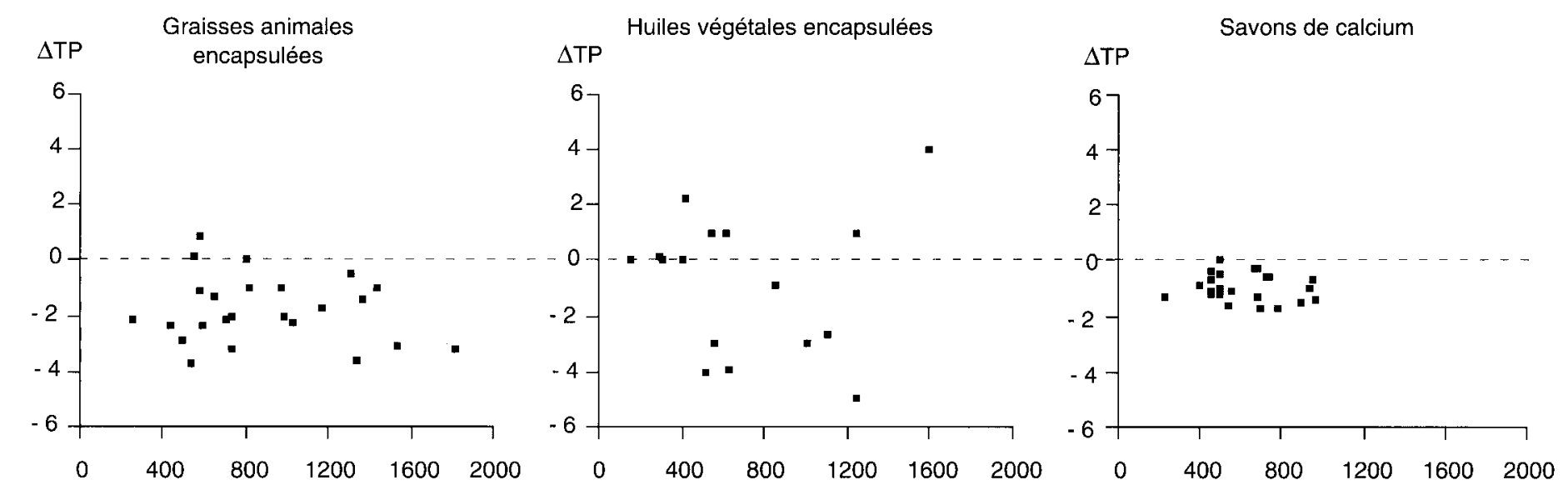
Tableau 3. Influence de la supplémentation en lipides encapsulés ou saponifiés (+ 630 à $730 \mathrm{~g} / \mathrm{j}$ d'acides gras) sur la composition (\% pondéral) des acides gras du lait.

\begin{tabular}{|c|c|c|c|c|c|c|c|c|}
\hline \multirow[t]{2}{*}{$\begin{array}{l}\text { Acides } \\
\text { gras }(\%)\end{array}$} & \multicolumn{2}{|c|}{ Suif encapsulé ${ }^{1}$} & \multicolumn{2}{|c|}{$\begin{array}{l}\text { Huile de soja } \\
\text { encapsulée }\end{array}$} & \multicolumn{2}{|c|}{$\begin{array}{l}\text { Huile de carthame } \\
\text { encapsulée }^{3}\end{array}$} & \multicolumn{2}{|c|}{$\begin{array}{l}\text { Savons de calcium } \\
\text { d'huile de palme }\end{array}$} \\
\hline & Témoin & $+730 \mathrm{~g} / \mathrm{j}$ & Témoin & $+630 \mathrm{~g} / \mathrm{j}$ & Témoin & $+630 \mathrm{~g} / \mathrm{j}$ & Témoin & $+650 \mathrm{~g} / \mathrm{j}$ \\
\hline $\mathrm{C} 4: 0$ & 3,5 & 3,1 & 1,4 & 1,7 & 3,6 & 1,6 & 2,9 & 3,3 \\
\hline C6:0 & 2,5 & 1,8 & 1,8 & 1,5 & 3,3 & 2,2 & 2,0 & 2,5 \\
\hline $\mathrm{C} 8: 0$ & 1,6 & 1,0 & 1,0 & 0,8 & 1,3 & 0,9 & 2,0 & 1,8 \\
\hline $\mathrm{C} 10: 0$ & 4,1 & 2,3 & 3,3 & 2,1 & 2,5 & 2,4 & 4,2 & 3,4 \\
\hline $\mathrm{C} 12: 0$ & 4,6 & 2,5 & 4,0 & 2,2 & 2,9 & 2,7 & 5,1 & 3,8 \\
\hline C14:0 & 12,2 & 8,4 & 12,2 & 7,1 & 10,4 & 8,3 & 12,0 & 10,4 \\
\hline $\mathrm{C} 16: 0$ & 29,8 & 27,4 & 29,0 & 17,5 & 30,4 & 15,6 & 31,6 & 33,3 \\
\hline C18:0 & 8,2 & 12,4 & 13,4 & 15,3 & 12,1 & 11,5 & 6,5 & 7,3 \\
\hline C18:1 & 20,4 & 28,9 & 24,6 & 32,8 & 24,2 & 24,2 & 19,6 & 23,0 \\
\hline $\mathrm{C} 18: 2$ & 2,1 & 1,9 & 7,6 & 16,2 & 2,6 & 24,6 & 2,8 & 2,8 \\
\hline $\mathrm{C} 18: 3$ & 0,2 & 0,2 & 1,9 & 3,0 & 1,7 & 2,4 & 0,2 & 0,2 \\
\hline $\begin{array}{l}\text { Matières grasses } \\
\text { du lait }(\mathrm{g} / \mathrm{j})\end{array}$ & s 799 & 901 & 930 & 1064 & 552 & 600 & 1065 & 1152 \\
\hline
\end{tabular}

${ }^{1}$ Storry et al 1980b, ${ }^{2}$ Mattos et Palmquist $1974,{ }^{3}$ Gooden et Lascelles $1973,{ }^{4}$ Chilliard et Fléchet non publié

du taux protéique des animaux recevant le régime témoin. Par ailleurs, la chute de taux protéique est plus réduite en début de lactation qu'après le pic (Doreau et al 1991).

Il est probable que la différence de réponse de taux protéique entre les trois classes de lipides protégés s'explique essentiellement par un effet de dilution lié aux différences de réponse de production laitière. Il a en effet été montré (Doreau et Chilliard 1992) que la chute du taux protéique consécutive à l'apport de lipides était liée pour une grande partie à l'accroissement de production laitière. Ceci se confirme dans le cas présent, puisque la supplémentation lipidique n'entraîne qu'une très légère tendance à la diminution de la sécrétion de protéines, de même amplitude pour les GAE, les HVE et les $\mathrm{SC}$ : respectivement 9,8 et $12 \mathrm{~g} / \mathrm{j}$.

\section{4 / Taux butyreux et composition des acides gras du lait}

\section{1 / Lipides encapsulés}

L'influence de l'encapsulation des lipides sur le taux butyreux est souvent positive. Ceci est vrai aussi bien avec les HVE (77 \% des essais, avec un effet moyen de $+6,4 \mathrm{~g} / \mathrm{kg}$ ) qu'avec les GAE (73\% des essais, avec un effet moyen de $+4,0 \mathrm{~g} / \mathrm{kg}$ ).

Le taux butyreux augmente linéairement avec les deux sources de lipides encapsulés, mais la réponse semble être plus forte avec les HVE (de 9,8 g/kg, par $\mathrm{kg}$ de HVE apportée, $\mathrm{r}=0,68$, figure 3 ) qu'avec les GAE (de 4,8 g/kg, par kg de GAE apportée, $r=0,70$ ). Cette dernière augmentation confirme les résultats obtenus par Storry et al (1980a) sur un nombre plus réduit de données. L'augmentation de la teneur en matières grasses du lait avec des suppléments de lipides encapsulés est un phénomène bien établi (Fogerty et Johnson 1980, Chilliard et al 1986). Il est dû essentiellement à l'augmentation du prélèvement mammaire des triglycérides des chylomicrons ou des lipoprotéines de très basse densité d'origine intestinale (Christie 1981), dont l'effet n'est que partiellement masqué par une baisse de la synthèse de novo d'acides gras. La moindre réponse du taux butyreux du lait avec les GAE résulte sans doute d'un effet dilution, puisque la production laitière augmente plus fortement avec cette source de matières grasses.

L'addition de suif encapsulé à la ration se traduit par une forte augmentation de la teneur des matières grasses du lait en acides stéarique et oléique ${ }^{(1)}$, compensée par une légère baisse de la teneur en acide palmitique (dont la sécrétion varie peu), et de fortes diminutions des teneurs et des sécrétions des acides gras à chaînes moyennes $(\mathrm{C} 6, \mathrm{C} 8$ et surtout C10 à C14) (tableau 3, Dunkley et al 1977, Sharma et al 1978, Smith et al 1978, Wrenn et al 1978, Storry et al 1980b). Ceci reflète une sécrétion accrue des acides gras longs du suif (C16:0, C18:0, C18:1) prélevés par la mamelle, qui inhibent par ailleurs la synthèse des acides gras à chaînes moyennes (C6 à C14). Pour ce qui concerne l'acide palmitique, la diminution de sa synthèse compense vraisemblablement entièrement l'augmentation de son prélèvement. Il est aussi à remarquer que l'augmentation de sécrétion du C18:1 est environ le double de celle du C18:0 (+97 vs $+46 \mathrm{~g} / \mathrm{j})$ alors que ces 2 acides gras sont apportés en quantités voisines par le suif. Ceci résulte probablement de la transformation en C18:1 d'une partie du C18:0 prélevé, par la delta 9-désaturase mammaire.

Les effets des suppléments d'HVE varient selon la nature des huiles, en relation avec leurs compositions en acides gras (tableaux 1, 


\section{Les acides gras du lait \\ (d'apres Chilliard et Sauvant 1987)}

Les matières grasses du lait se composent essentiellement de tríglycérides ( $98 \%$ chez la vache) dont la composition en acides gras est très variable d'une espèce à lautre. Les ruminants se caractérisent par la richesse de leurs triglycérides en acides gras courts et moyens (de 4 a 14 atomes de carbone) et en acides gras mineurs (impairs et ramifiés), et de très faibles teneurs en acides gras longs polyinsaturés à 18 atomes de carbone.

Les acides gras sécrétés par la mamelle ont une double origine. Ils proviennent soit des acides gras longs sanguins, soit d'une synthèse de novo par les cellules mammaires à partir de précurseurs ayant 2 ou 4 atomes de carbone.

Les acides gras d'origine sanguine représentent environ $60 \%$ (en poids) des acides gras sécrétés dans le lait (50\% en moles). Ces acides gras possèdent au moins 12 atomes de carbone et ils représentent $60 \%$ environ de lacide palmitique et la quasi-totalité des acides gras a 18 atomes de carbone du lait. Ce sont essentiellement les triglycérides des lipoprotéines de trés faible densité (prélevés après action de la lipoprotéine-lipase) et les acides gras non estérifiés du sang qui véhiculent les acides gras potentiellement utilisables par la mamelle. La pauvreté en acides gras longs polyinsaturés du lait de ruminant s'explique par la biohydrogénation des acides gras alimentaires dans le rumen, ainsi que par la pauvreté des triglycérides et des acides gras non estérifiés circulants en ces acides gras, qui sont surtout transportés sous forme d'esters du cholestérol ou de phospholipides très peu prélevés par la mamelle.

La synthèse mammaire des acides gras du lait de ruminant s'effectue a partir d'acétate 2 atomes de carbone) et de 3 -hydroxybutyrate ( 4 atomes de carbone) et non à partir de glucose comme cela se passe chez la plupart des espèces monogastriques. Le 3-hydroxybutyrate est à l'origine d'environ 15 $\%$ des atomes de carbone des acides gras synthétisés. Ces particularités des ruminants leur permettent d'épargner du glucose, utilisé prioritairement pour la synthèse du lactose, et de valoriser lacétate et le 3 -hydroxybutyrate qui sont disponibles en quantités importantes du fait de la fermentation réticulo-ruminale des glucides alimentaires. La synthèse de novo d'acides gras est toutefois inhibée par les acides gras à longue chaine.

La lipogénèse dans le tissu mammaire donne naissance à des acides gras ayant de 4 à 16 atomes de carbone, alors que dans les autres tissus, ce sont les acides gras à 16 et 18 atomes de carbone qui prédominent largement. Par ailleurs, l'acide stéarique prélevé dans le sang peut être très largement désaturé en acide oléique. Enfin, la synthèse des triglycérides aboutit à la formation de molécules asymétriques, avec notamment une estérification préférentielle des acides gras à courte chaîne ( $\mathrm{C} 4$ - C6) sur position 3 de la molécule de glycérol. Tous ces phénomènes concourent à abaisser le point de fusion des matières grasses du lait (atténuant ainsi les effets des hydrogénations ruminales) qui demeurent liquides à la température cellulaire intra-mammaire et sont probablement mieux utilisables par le nouveau-né.

3 et 4$)$. Toutefois, la protection contre la biohydrogénation ruminale étant généralement imparfaite, on peut observer un effet moins positif qu'escompté sur les acides gras polyinsaturés du lait, généralement au profit de l'acide stéarique et des acides gras monoinsaturés de structure trans. La supplémentation en huile de soja encapsulée (riche en C18:1 et surtout en C18:2, ainsi qu'en C18:3) accroît surtout les teneurs et les sécrétions de C18:2, C18:1 et C18:0, au détriment des acides gras de C10 à C16 (tableau 3, Bitman et al 1973, Mattos et Palmquist 1974, Goering et al 1977). L'apport d'huile de carthame (riche en C18:1 et surtout C18:2) entraîne une augmentation considérable de la teneur et de la sécrétion de C18:2 du lait sans modifier celles des autres acides gras à 18 atomes de carbone (ce qui témoigne d'une bonne protection dans l'essai de Gooden et Lascelles (1973) rapporté dans le tableau 3 ), et au détriment de l'acide palmitique et, dans une moindre mesure, des acides gras de $\mathrm{C} 4$ à C14.

Dans le cas d'une infusion duodénale d'huile de colza (riche en C18:1, ainsi qu'en C18:2 et C18:3), on observe des accroissements importants des teneurs et des sécrétions de ces trois acides gras, au détriment de l'acide palmitique principalement (tableau 4, Chilliard et al 1991, Chilliard et Doreau 1991 et non publié). Des résultats allant dans le même sens, quoique de moindre ampleur, sont obtenus avec de l'huile de colza encapsulée par une technique assurant $85 \%$ de protection in vitro et $65 \%$ in vivo (Ashes et al 1992). Par contre, avec de l'huile de colza moins bien encapsulée (tableau 4 , Atwal et al 1991), les augmentations des teneurs en C18:2 et C18:3 sont très faibles alors que les concentrations de C18:1 et de C18:0 augmentent largement, au détriment des acides gras de C6 à C16. La comparaison indirecte des résultats d'infusion et d'apport d'huile encapsulée suggère aussi que l'effet inhibiteur sur la synthèse des acides gras à chaîne courte et moyenne pourrait être plus net lorsque le métabolisme ruminal est perturbé (ce qui est souvent le cas lorsque des lipides encapsulés sont distribués), ce qui expliquerait la moindre sécrétion de matières grasses enregistrée par Atwal et al (1991). En distribuant de l'huile de colza non protégée, Kankare et al (1989, tableau 4) rapportent des augmentations modestes des teneurs en C18:0 et C18:1, au détriment de celles des acides gras de C12 à $\mathrm{C} 16$, et dans une moindre mesure de C4 à C10.

\section{L'addition de lipides encapsulés augmente fortement le taux butyreux, de $4,0 \mathrm{~g} / \mathrm{kg}$ pour les graisses et de 6,4 g/kg pour les huiles.}


Tableau 4. Influence de la supplémentation en huile de colza (+570 à $836 \mathrm{~g} / \mathrm{j})$ sous différentes formes sur la composition (\% pondéral) des acides gras du lait.

\begin{tabular}{|c|c|c|c|c|c|c|c|c|}
\hline \multirow{2}{*}{$\begin{array}{l}\text { Acides } \\
\text { gras }(\%)\end{array}$} & \multicolumn{2}{|c|}{ Huile non protégée ${ }^{1}$} & \multicolumn{2}{|c|}{ Savons de calcium ${ }^{1}$} & \multicolumn{2}{|c|}{ Huile encapsulée $^{2}$} & \multicolumn{2}{|c|}{ Huile infusée $^{3}$} \\
\hline & Témoin & $+620 \mathrm{~g} / \mathrm{j}$ & Témoin & $+570 \mathrm{~g} / \mathrm{j}$ & Témoin & $+836 \mathrm{~g} / \mathrm{j}$ & Témoin & $+630 \mathrm{~g} / \mathrm{j}$ \\
\hline $\mathrm{C} 4: 0$ & & & & & - & - & 3,0 & 3,1 \\
\hline C6:0 & 11,3 & 10,8 & 11,4 & 12,9 & 1,0 & 0,7 & 2,2 & 2,3 \\
\hline C8:0 & & & & & 0,8 & 0,5 & 2,1 & 2,3 \\
\hline $\mathrm{C} 10: 0$ & & & & & 2,2 & 1,2 & 4,4 & 4,1 \\
\hline $\mathrm{C} 12: 0$ & 4,1 & 3,5 & 3,9 & 4,1 & 3,0 & 1,4 & 4,8 & 4,7 \\
\hline $\mathrm{C} 14: 0$ & 12,5 & 11,6 & 12,5 & 12,7 & 11,6 & 6,4 & 12,2 & 10,8 \\
\hline $\mathrm{C} 16: 0$ & 30,1 & 25,5 & 30,7 & 27,4 & 32,9 & 19,8 & 33,7 & 26,2 \\
\hline $\mathrm{C} 18: 0$ & 10,9 & 12,8 & 11,6 & 9,5 & 14,9 & 24,0 & 7,6 & 7,7 \\
\hline C18:1 & 20,3 & $25,3^{4}$ & 19,6 & $21,7^{5}$ & 25,4 & 37,5 & 18,1 & 23,3 \\
\hline $\mathrm{C} 18: 2$ & 2,2 & 2,2 & 2,1 & 2,8 & 2,7 & 3,8 & 1,9 & 6,4 \\
\hline C18:3 & 0,5 & 0,5 & 0,5 & 0,4 & 0,4 & 0,8 & 0,2 & 2,8 \\
\hline $\begin{array}{l}\text { Matières } \\
\text { grasses } \\
\text { du lait (g/j) }\end{array}$ & $\mathrm{np}$ & $n p$ & $\mathrm{np}$ & $\mathrm{np}$ & 1100 & 914 & 976 & 1047 \\
\hline
\end{tabular}

${ }^{1}$ Kankare et al $1989,{ }^{2}$ Atwal et al $1991,{ }^{3}$ Infusion duodénale, Chilliard et Doreau 1991 et non publié, ${ }^{4} \mathrm{C} 18: 1$ cis, $+4 \%, \mathrm{C} 18: 1$ trans, $+1 \% ;{ }^{5} \mathrm{C} 18: 1$ cis, $-0,6 \%$; C18:1 trans, $+2,7 \% ; \mathrm{np}=$ non précisé

L'accroissement de taux butyreux s'est produit quel que soit le taux butyreux du régime témoin. Ceci montre qu'il ne semble pas y avoir de mécanisme de régulation étroite du prélèvement mammaire d'acides gras longs, dans le cas où la composition de ceux-ci est compatible avec le maintien d'un point de fusion suffisamment bas des matières grasses ne limitant pas leur sécrétion : c'est le cas des acides gras à 18 atomes de carbone, saturés ${ }^{(2)}$ ou insaturés, à l'exception des acides gras insaturés de structure trans (Chilliard et al 1986). L'accroissement particulièrement important du taux butyreux avec les HVE pourrait donc être dû en partie au point de fusion très bas des acides gras polyinsaturés, le moindre effet sur la production laitière pouvant résulter soit de limites à l'oxydation des acides gras polyinsaturés chez le ruminant (adapté à les épargner), soit de l'existence d'autres facteurs limitants particuliers aux expériences "HVE" considérées dans cette étude.

De cet ensemble de données, on peut conclure que la réponse du taux butyreux à un apport de lipides encapsulés diffère de la réponse obtenue avec des lipides non protégés. Celle-ci est peu marquée en moyenne, mais très variable d'un essai à l'autre (Chilliard et al 1986, Hermansen et Pedersen 1987). Le taux butyreux peut décroître fortement, en particulier lorsque la source de lipides perturbe la digestion ruminale, et réduit donc la production de précurseurs d'acides gras du lait : acétate et $\beta$-hydroxybutyrate, ou bien dans le cas où la production ruminale d'acides gras de structure trans est largement accrue, ceux-ci ayant un effet inhibiteur plus marqué sur la synthèse de novo d'acides gras.

\section{2 / Savons de calcium}

Le taux butyreux n'est généralement pas augmenté par les SC à base d'huile de palme $(r=0,23, P>0,10$, figure 3 ) lorsqu'ils sont ajoutés à la ration à raison de 200 à $900 \mathrm{~g} / \mathrm{j}$. L'effet des SC est non significatif dans $72 \%$ des essais étudiés (tableau 2). La différence de comportement des SC par rapport aux lipides encapsulés ne semble pas due aux doses employées, plus faibles dans le cas des SC, car, avec les mêmes doses (400 à $1000 \mathrm{~g} / \mathrm{j})$, le taux butyreux s'accroît avec les GAE et les HVE (figure 3).

La supplémentation en SC d'huile de palme (riches en C16:0 et C18:1, et dans une moindre mesure en C18:2) accroît les teneurs et les sécrétions de C18:1 et de C16:0, et dans une moindre mesure de $\mathrm{C} 18: 0$, au détriment des acides gras de $\mathrm{C} 10$ à C14 (tableau 3 ). L'ensemble de résultats du tableau 5 montre toutefois que les réponses respectives des teneurs en C18:1, C18:0 et $\mathrm{C} 16: 0$ sont assez variables d'un essai à l'autre. Les accroissements sont toutefois plus constants pour le C18:1 et le $\mathrm{C} 16: 0$ que pour le C18:0. La réponse relativement faible du C16:0 par rapport à la richesse de l'huile de palme en cet acide gras peut s'expliquer par l'inhibition simultanée de sa synthèse de novo. Par contre, le C18:2 n'est jamais accru au-delà de $+0,4 \%$ (tableau 5), ce qui suggère que les savons de calcium de l'acide linoléique contenu dans l'huile de palme ne sont pas protégés efficacement contre la biohydrogénation ruminale. Ceci a été confirmé récemment avec des savons de calcium d'huile de colza qui n'augmentent pas significativement la sécrétion de C18:2 du lait, mais accroissent celle de C18:1 de structure trans (tableau 4, Kankare et al 1989, Ferlay et al 1992), en accord avec des études directes sur la biohydrogénation ruminale (Ferlay et al 1992). 
Tableau 5. Influence de la supplémentation en savons de calcium d'huile de palme sur la composition en acides gras du lait à 16 et 18 atomes de carbone.

\begin{tabular}{|lccccc|}
\hline Référence & $\begin{array}{c}\text { Niveau } \\
\text { de supplémentation } \\
\text { (g/j) }\end{array}$ & \multicolumn{3}{c|}{ Réponse des acides gras du lait $^{1}$} \\
& & $\mathbf{C 1 6 : 0}$ & $\mathbf{C 1 8 : 0}$ & $\mathbf{C 1 8 : 1}$ & $\mathbf{C 1 8 : 2}$ \\
\hline Schneider et al (1988) & 800 & $+2,2$ & $-0,6$ & $-1,1$ & $+0,4$ \\
Atwal et al (1990) & 950 & $+2,2$ & $+0,3$ & $+4,8$ & $+0,1$ \\
Schneider et al (1990) & 770 & $+2,8$ & $-1,0$ & $+1,8$ & $+0,4$ \\
West et Hill (1990) & 400 & $+2,3$ & $-0,2$ & $+1,8$ & $-0,2$ \\
Chilliard, Fléchet, Doreau (non publié) & 870 & $+1,3$ & $+1,8$ & $+2,8$ & $+0,1$ \\
Chilliard et Fléchet (non publié) & 780 & $+1,7$ & $+0,8$ & $+3,4$ & 0 \\
\hline Moyenne & 762 & $+2,1$ & $+0,2$ & $+2,2$ & $+0,1$ \\
(écart type) & $(190)$ & $(0,5)$ & $(1,0)$ & $(2,0)$ & $(0,2)$ \\
\hline
\end{tabular}

$1 \%$ pondéral (lot supplémenté - lot témoin)

L'absence de réponse positive du taux butyreux relevée avec les SC pourrait aussi être liée au fait que l'acide palmitique, majoritaire dans ce type de supplément lipidique, est beaucoup moins facilement désaturé par la glande mammaire que l'acide stéarique (Bickerstaffe et Annison 1968). Une large incorporation de C16:0 dans les triglycérides du lait tendrait à augmenter le point de fusion des matières grasses, et donc à limiter leur sécrétion, ce qui explique que la synthèse de novo de $\mathrm{C} 16: 0$ soit réduite simultanément à l'accroissement du prélèvement de cet acide gras. Par contre, l'oxydation des acides gras non sécrétés dans le lait permet de fournir de l'énergie à l'organisme tout en épargnant du glucose, ce qui explique les effets positifs sur le volume du lait produit. Ces hypothèses demandent toutefois à être confirmées, notamment en comparant des SC d'huile de palme avec des $\mathrm{SC}$ de matières grasses riches en acides gras à 18 atomes de carbone, et ne perturbant pas les fermentations ruminales.

\section{Conclusion}

A l'examen des résultats expérimentaux, il apparaît que les principales réponses zootechniques à l'incorporation de lipides protégés (ingestion de matière sèche, production laitière, taux protéique) sont similaires à celles qui sont observées avec des lipides non protégés (Palmquist 1984b). L'intérêt principal des lipides protégés résiderait ainsi dans un moindre risque quant à une éventuelle diminution de la digestion ruminale, et serait donc d'atteindre l'un des objectifs de la supplémentation lipidique, à savoir l'accroissement de la concentration énergétique de la ration. Cet objectif ne peut toutefois pas être atteint pleinement du fait que la plupart des techniques d'encapsulation ne protègent que partiellement les lipides. En outre, les animaux diminuent leur niveau d'ingestion, ce qui limite l'accroissement potentiel de l'ingestion d'énergie que l'on peut escompter en distribuant des lipides efficacement encapsulés ou saponifiés. Cependant, l'utilisation de lipides encapsulés, à l'exception probable des produits à base d'huile de palme, peut permettre d'accroître le taux butyreux et la proportion d'acides gras insaturés dans le lait. L'intérêt de telles modifications n'est peut-être pas évident dans les conditions actuelles de production, mais mérite d'être retenu dans le cadre d'une réflexion globale sur la maîtrise de la composition du lait de vache.

\section{Références bibliographiques}

Ashes J.R., Gulati S.K., Cook L.J., Scott T.W., Donnelly J.B., 1979. Assessing the biological effectiveness of protected lipid supplements for ruminants. J. Am. Oil Chem. Soc., 56, 522-527.

Ashes J.R., St. Vincent Welch P., Gulati S.K., Scott T.W., Brown G.H., Blakeley S., 1992. Manipulation of the fatty acid composition of milk by feeding protected canola seeds. J. Dairy Sci., 75, 1090-1096.

Astrup H.N., Vik-Mo L., Lindstad P., Ekern A., 1979. Casein protected oil supplement fed at a low level to milk cows. Milchwissenschaft, 34, 290-291.

Atwal A.S., Hidiroglou M., Kramer J.K.G., Binns M.R., 1990. Effects of feeding a-tocopherol and calcium salts of fatty acids on vitamin $E$ and fatty acid composition of cow's milk. J. Dairy Sci., 73, 2832-2841.

Atwal A.S., Hidiroglou M., Kramer J.K.G., 1991. Effects of feeding Protec and a-tocopherol on fatty acid composition and oxidative stability of cow's milk. J. Dairy Sci., 74, 140-145.

Baker J.G., Tomlinson J.E., Johnson D.D., Boyd M.E., 1989. Influence of two whole oilseed sources supplemented with Megalac on the performance and milk composition of early lactation cows. J. Dairy Sci., 72 (Suppl.1), 483 (Abstr.).

Banks W., Clapperton J.L., Girdler A.K., Steele W., 1984. Effect of inclusion of different forms of dietary fatty acid on the yield and composition of cow's milk. J. Dairy Res., 51, 387-395. 
Barbano D.M., Sherbon J.W., 1980. Polyunsaturated protected lipid : effect on triglyceride molecular weight distribution. J. Dairy Sci., 63, 731-740.

Bickerstaffe R., Annison E.F., 1968. The desaturation of stearic acid by mammary-gland tissue of the lactating goat and sow. Biochem. J., $108,47 \mathrm{P}-48 \mathrm{P}$

Bines J.A., Brumby P.E., Storry J.E., Fulford R.J., Braithwaite G.D., 1978. The effect of protected lipids on nutrient intakes, blood and rumen metabolites and milk secretion in dairy cows during early lactation. J. Agric. Sci., Camb., 91, 135-150.

Bitman J., Dryden L.P., Goering H.K., Wrenn T.R., Yoncoskie R.A., Edmonson L.F., 1973. Efficiency of transfer of polyunsaturated fats into milk. J. Am. Oil Chem. Soc., 50, 93-98.

Burgess P.L., Muller L.D., Varga G.A., Griel L.C.Jr., 1987. Addition of calcium salts of fatty acids to rations varying in neutral detergent fiber content for lactating dairy cows. J. Dairy Sci., 70 (Suppl.1), 220 (Abstr.).

Chilliard Y., 1993. Dietary fat and adipose tissue metabolism in ruminants, pigs and rodents : a review. J. Dairy Sci., sous presse.

Chilliard Y., Doreau M., 1991. Influence of a duodenal infusion of rapeseed oil and amino acids on cow milk yield and composition. Proc. 42nd Ann. Meet. Eur. Assoc. Anim. Prod., Berlin, Germany, vol. $2,26-27$

Chilliard Y., Sauvant D., 1987. La sécrétion des constituants du lait. in : Le Lait, matière première de l'industrie laitière. INRA-CEPIL, Paris, p. 13-26.

Chilliard Y., Morand-Fehr P., Sauvant D., Bas P., 1986. Utilisation métabolique des lipides par le ruminant en lactation. Bull. Tech. CRZV Theix, INRA, 63, 81-91.

Chilliard Y., Gagliostro G., Fléchet J., Lefaivre J., Sebastian I., 1991. Duodenal rapeseed oil infusion in early and midlactation cows. 5. Milk fatty acids and adipose tissue lipogenic activities. J. Dairy Sci., 74 , 1844-1854.

Christie W.W., 1981. The effects of diet and other factors on the lipid composition of ruminant tissues and milk. In : Lipid Metabolism in Ruminant Animals. Christie W.W. (ed.), Pergamon Press, Oxford, 193-226.

Crovetto G.M., Sandrucci A., Steffanini L., Modenesi R., Corti M., 1989. Influence of protected fat (Casoaps) on milk production in dairy cows. Proc. 40th Ann. Meet. Eur. Assoc. Anim. Prod., Dublin, Ireland, 371-372

Devendra C., Lewis D., 1974. The interaction between dietary lipids and fibre in the sheep. 2 . Digestibility studies. Anim. Prod., 19, 67-76.

Doreau M., Chilliard Y., 1992. Influence d'une supplémentation de la ration en lipides sur la qualité du lait chez la vache. INRA Prod. Anim., 5, 103-111.

Doreau M., Chilliard Y., Bauchart D., Morand-Fehr P., 1987. Besoins en lipides des ruminants. Bull. Tech. CRZV Theix, INRA, 70, 91-97.

Doreau M., Chilliard Y., Bauchart D., MichaletDoreau B., 1991. Influence of different fat supplements on digestibility and ruminal digestion in cows. Ann. Zootech., 40, 19-30.
Doreau M., Elmeddah Y., Chilliard Y., 1991. Influence of a calcium salt supplementation on milk yield and composition, according to basal diet and lactation stage. Proc. 42nd Ann. Meet. Eur. Assoc. Anim. Prod., Berlin, Germany, Vol. 2, 38-39.

Downer J.V., Kutches A.J., Cummins K.R., Chalupa W., 1987. High fat rations for lactating cows supplemented with the calcium salts of long chain fatty acids. J. Dairy Sci., 70 (Suppl.1), 221 (Abstr.).

Dunkley W.L., Smith N.E., Franke A.A., 1977. Effects of feeding protected tallow on composition of milk and milk fat. J. Dairy Sci., 60, 1863-1869.

Eastridge M.L., Palmquist D.L., 1988. Supplemental energy as calcium soaps beginning at two or six weeks of lactation. J. Dairy Sci., 71 (Suppl.1), 254 (Abstr.).

Elmeddah Y., Doreau M., Michalet-Doreau B., 1991. Interaction of lipid supply and carbohydrates in the diet of sheep with digestibility and ruminal digestion. J. Agric Sci., Camb. 116, 437-445.

Erickson P.S., Murphy M.R., Clark J.H., 1992. Supplementation of dairy cow diets with calcium salts of long-chain fatty acids and nicotinic acid in early lactation. J. Dairy Sci., 75, 1078-1089.

Ferguson J.D., Torralba J., Schneider P.L., Vecchiarelli B., Sklan D., Kronfeld D.S., Chalupa W., 1988. Response of lactating cows in commercial dairies to calcium salts of long chain fatty acids. J. Dairy Sci., 71 (Suppl.1), 254 (Abstr.).

Ferguson J.D., Sniffen C.J., Muscato T., Pilbeam T., Sweeney T., 1989. Effects of protein degradability and protected fat supplementation on milk yield in dairy cows. J. Dairy Sci., 72 (Suppl.1), 415 (Abstr).

Ferlay A., Chilliard Y., Doreau M., 1992. Effects of calcium salts differing in fatty acid composition on duodenal and milk fatty acid profiles in dairy cows. J. Sci. Food Agric., 60, 31-37.

Fogerty A.C., Johnson A.R., 1980. Influence of nutritional factors on the yield and content of milk fat : protected polyunsaturated fat in the diet. Int. Dairy Fed. Bull., 125, 96-104.

Gagliostro G., Chilliard Y., 1991. Duodenal rapeseed oil infusion in early and midlactation cows. 2. Voluntary intake, milk production and composition. J. Dairy Sci., 74, 499-509.

Goering H.K., Gordon C.H., Wrenn T.R., Bitman J., King R.L., Douglas F.W.Jr., 1976. Effect of feeding protected safflower oil on yield, composition, flavor and oxidative stability of milk. J. Dairy Sci., 59, 416425 .

Goering H.K., Wrenn T.R., Edmonson L.F., Weyant J.R., Wood D.L., Bitman J., 1977. Feeding polyunsaturated vegetable oils to lactating cows. J. Dairy Sci., 60, 739-747.

Gooden J.M., Lascelles A.K., 1973. Effect of feeding protected lipid on the uptake of precursors of milk fat by the bovine mammary gland. Aust. J. biol. Sci., $26,1201-1210$.

Grummer R.R., 1988. Influence of prilled fat and calcium salt of palm oil fatty acids on ruminal fermentation and nutrient digestibility. J. Dairy Sci., 71, 117-123. 
Grummer R.R., Armentano L.E., Marcus M.S., 1987. Lactation response to short-term abomasal infusion of choline, inositol, and soy lecithin. J. Dairy Sci., 70, 2518-2524.

Harris B.Jr., Webb D.W., 1988. Effect of feeding high fat rations to early lactating cows supplemented with Megalac in a large dairy. J. Dairy Sci., 71 (Suppl.1), 274 (Abstr.).

Hermansen J.E., Pedersen J., 1987. Milk composition in relation to breeding and feeding. In Research in cattle production. Danish status and perspectives. Landhusholdningsselskabets Forlag., Copenhague, pp. 140-154.

Kankare V., Antila V., Vaatainen H., Miettinen H., Setala J., 1989. The effect of calcium salts of fatty acids added to the feed of dairy cows on the fatty acid composition of milk fat. Finnish J. Dairy Sci., $47,1-9$.

Karleskind A., 1992. Manuel des Corps Gras, 2 vol. Ed. Lavoisier, Paris.

Kent B.A., Arambel M.J., 1988. Effect of calcium salts of long-chain fatty acids on dairy cows in early lactation. J. Dairy Sci., 71, 2412-2415.

Klusmeyer T.H., Clark J.H., 1991. Effects of dietary fat and protein on fatty acid flow to the duodenum and in milk produced by dairy cows. J. Dairy Sci., $74,2220-2232$.

Klusmeyer T.H., Lynch G.L., Clark J.H., Nelson D.R., 1989. Effect of amount of forage and calcium salts of long chain fatty acids (Ca-LCFA) on ruminal fermentation and flow of nutrients to the small intestine of lactating dairy cows. J. Dairy Sci., 72 (Suppl.1), 482 (Abstr.).

Kronfeld D.S., Donoghue S., Naylor J.M., Johnson K., Bradley C.A., 1980. Metabolic effects of feeding protected tallow to dairy cows. J. Dairy Sci., 63, 545552.

Mac Leod G.K., Yu Y., Schaeffer L.R., 1977. Feeding value of protected animal tallow for high yielding dairy cows. J. Dairy Sci., 60, 726-738.

Mattos W., Palmquist D.L., 1974. Increased polyunsaturated fatty acid yields in milk of cows fed protected fat. J. Dairy Sci., 57, 1050-1054.

Murphy J.J., Morgan D.J., 1983. Effect of inclusion of protected and unprotected tallow in the supplement on the performance of lactating dairy cows. Anim. Prod., 37, 203-210.

Palmquist D.L., 1984a. Calcium soaps of fatty acids with varying unsaturation as fat supplements for lactating cows. Can. J. Anim. Sci., 64 (Suppl.), 240241.

Palmquist D.L., 1984b. Use of fats in diets for lactating dairy cows. In : Fats in animal nutrition. J Wiseman, (ed.), Butterworths, London, 357-381.

Palmquist D.L., 1988. Effects of calcium salts of isoacids and palm fatty acid distillate on feed intake, rumen fermentation and milk yield in early lactation. J. Dairy Sci., 71 (Suppl.1), 254 (Abstr.).

Palmquist D.L., Jenkins T.C., 1980. Fat in lactation rations. Review. J. Dairy Sci., 63, 1-14.

Palmquist D.L., Jenkins T.C., 1982. Calcium soaps as a fat supplement in dairy cattle feeding. XII World Congr. Diseases of cattle, 477-481.
Palmquist D.L., Moser E.A., 1981. Dietary fat effects on blood insulin, glucose utilization, and milk protein content of lactating cows. J. Dairy Sci., 64, 1664-1670.

Pan S.P., Cook L.J., Scott T.W., 1972. Formaldehyde-treated casein-safflower oil supplement for dairy cows. I. Effect on milk composition. J. Dairy Res., 39, 203-207.

Plowman R.D., Bitman J., Gordon C.H., Dryden L.P., Goering H.K., Wrenn T.R., Edmondson L.H., Yoncoskie R.A., Douglas F.W., 1972. Milk fat with increased polyunsaturated fatty acids. J. Dairy Sci., $55,204-207$.

Radcliffe J.D., Bartsch B.D., 1975. Yield, composition, fatty acid unsaturation, and stability of milk from cows fed protected sunflower seed supplements when grazing green oats. J. Dairy Sci., 58, 759 (Abstr.).

Rindsig R.B., Schultz L.H., 1974. Effects of abomasal infusions of safflower oil or elaidic acid on blood lipids and milk fat in dairy cows. J. Dairy Sci., 57, 1459-1466.

Robb E.J., Chalupa W., 1987. Lactational responses in early lactation to calcium salts of long chain fatty acids. J. Dairy Sci., 70 (Suppl.1), 220 (Abstr.).

Schauff D.J., Clark J.H., 1989. Effects of prilled fatty acids and calcium salts of fatty acids on rumen fermentation, nutrient digestibilities, milk production and milk composition. J. Dairy Sci., 72, 917-927.

Schneider P.L., Sklan D., Chalupa W., Kronfeld D.S., 1988. Feeding calcium salts of fatty acids to lactating cows. J. Dairy Sci., 71, 2143-2150.

Schneider P.L., Sklan D., Kronfeld D.S., Chalupa W., 1990. Responses of dairy cows in early lactation to bovine somatotropin and ruminally inert fat. J. Dairy Sci., 73, 1263-1268.

Scott T.W., Cook L.J., Mills S.C., 1971. Protection of dietary polyunsaturated fatty acids against microbial hydrogenation in ruminants. J. Am. Oil Chem. Soc., 48, 358-364.

Sharma H.R., Ingalls J.R., Mc Kirdy J.A., 1978. Replacing barley with protected tallow in ration of lactating Holstein cows. J. Dairy Sci., 61, 574-583.

Smith N.E., Dunkley W.L., Franke A.A., 1978. Effects of feeding protected tallow to dairy cows in early lactation. J. Dairy Sci., 61, 747-756.

Storry J.E., Brumby P.E., Hall A.J., Johnson V.W., 1974. Response of the lactating cow to different methods of incorporating casein and coconut oil in the diet. J. Dairy Sci., 57, 61-67.

Storry J.E., Brumby P.E., Dunkley W.L., 1980a. Influence of nutritional factors on the yield and content of milk fat : protected non-polyunsaturated fat in the diet. Int. Dairy Fed. Bull., 125, 105-125.

Storry J.E., Brumby P.E., Tuckley B., Welch V.A., Stead D., Fulford R.J., 1980b. Effect of feeding protected lipid to dairy cows in early lactation on the composition of blood lipoproteins and secretion of fatty acids in milk. J. Agric. Sci. (Camb.), 94, 503-516.

Tamminga S., Doreau M., 1991. Lipids and rumen digestion. in : Rumen microbial metabolism and ruminant digestion. J. P. Jouany, (ed.), p. 151, INRA, Paris, France. 
Umphrey J.E., Moss B.R., Cummins K.A., Coleman D.A., 1989. Effects of whole cottonseed, Megalac or the combination on lactational performance of dairy cows during summer months. J. Dairy Sci., 72, 2205 (Abstr.).

Vermorel M., Sauvant D., Michalet-Doreau B., 1986. Valeur énergétique des matières grasses de la ration des vaches laitières. Bull. Tech. CRZV Theix, INRA, $66,67-73$

Vicente G.R., Shelford J.A., Peterson R.G. Krishnamurti C.R., 1984. Effects of feeding canolameal-protected-tallow or soybean-meal-protected tallow in the low-roughage diet of dairy cows in early lactation. Can. J. Anim. Sci., 64, 81-91.
West J.W., Hill G.M., 1990. Effect of a protected fat product on productivity of lactating Holstein and Jersey cows. J. Dairy Sci., 73, 3200-3207.

Wilson G.F., Brookes I.M., 1975. The influence of a protected tallow supplement on milk yield and composition. Proc. N. Z. Soc. Anim. Prod., 35, 41-46.

Wrenn T.R., Weyant J.R., Wood D.L., Bitman J., Rawlings R.M., Lyon K.E., 1976. Increasing polyunsaturation of milk fats by feeding formaldehyde protected sunflower-soybean supplement. J. Dairy Sci., 59, 627-635.

Wrenn T.R., Bitman J., Waterman R.A., Weyant J.R., Wood D.L., Strozinski L.L., Hooven N.W.Jr. 1978. Feeding protected and unprotected tallow to lactating cows. J. Dairy Sci., 61, 49-58.

\section{Summary}

Protected (encapsulated or calcium salts) lipids in dairy cow diets. Effects on production and milk composition.

A limitation to an extensive use of fat in ruminant diets is the subsequent disturbance of carbohydra te ruminal digestion. In order to overcome this problem, different kinds of protection of lipids have been proposed. This paper summarizes the effects of the addition of encapsulated animal fats $(941 \mathrm{~g} /$ day on average) and vegetable oils (693 $\mathrm{g} /$ day), as well as calcium salts ( $593 \mathrm{~g} /$ day) in dairy cow diets, on feed intake, milk production and composition.

Addition of protected fats decreases food intake, less for calcium salts $(0.55 \mathrm{~kg} \mathrm{DM} /$ day) than for encapsulated animal fats (1.1 kg DM/day) or vegetable oils $(1.3 \mathrm{~kg} \mathrm{DM} /$ day). These decreases are comparable to those observed with non protected fat.

Encapsulated animal fats or calcium salts increase milk yield by approximately $1 \mathrm{~kg} /$ day, when encapsulated vegetable oils do not modify it. Addition of encapsulated animal fats or calcium salts decreases milk protein content by 1.8 and $1.2 \mathrm{~g} / \mathrm{kg}$, respectively, when encapsulated vegetable fat does not modify it. This difference is a consequence of variations in milk yield : total protein output does not vary with any of the three supplements. An important increase in milk butterfat is observed with encapsulated animal fat $(4.0 \mathrm{~g} / \mathrm{kg})$ and vegetable oils $(6.4 \mathrm{~g} / \mathrm{kg})$. The increase in long-chain fatty acids is higher than the decrease in de novo synthesis of short- and mediumchain fatty acids. Increase in the polyunsaturated fatty acid output is a criterion of the extent of protection of lipids against ruminal hydrogenation. Addition of calcium salts does not modify milk butterfat. According to the experiments, inhibition of de novo synthesis is compensated for by an increase in secretion either of palmitic acid, or of oleic acid.

CHILLIARD Y., DOREAU M., GAGLIOSTRO G., ELMEDDAH Y., 1993. Addition de lipides protégés (encapsulés ou savons de calcium) à la ration de vaches laitières. Effets sur les performances et la composition du lait. INRA Prod. Anim., 6 (2), 139 - 150. 